\title{
Hesa-A Down-Regulates erb/b2 Oncogene Expression and Improves Outcome of Oral Carcinoma in a Rat Model
}

\author{
Mehran Mesgari Abbasii, ${ }^{1,2}$, Masoumeh Mehdipour ${ }^{3}$, Amir Monfaredan $^{4}$, Rana \\ Jahanban-Esfahlan ${ }^{2,5 *}$
}

\begin{abstract}
Background: Oral carcinoma (OC) remains one of the most difficult malignancies to cure. Hesa-A is an Iranian herbal-marine compound that has shown promising anti-tumor properties against various human tumors. However, its mechanism of action remains to be addressed. The present study was conducted to evaluate the effect of two doses of Hesa-A on mRNA expression of erb $\backslash b 2$ as a main prognosticator tumor marker for OC in an animal model. Materials and Methods: A total of 60 rats were randomly divided into 5 groups of 12 animals each. Rats in carcinoma groups received 0,250 and $500 \mathrm{mg} / \mathrm{kg}$ body weight doses of Hesa-A 3 times a day. The other two groups were considered as treated and untreated control groups. At the end of the experiment, animals were sacrificed and tongue tissues subjected to $H$ and $E$ staining and real time PCR. Results: Our results showed that compared to the control group, erb $\backslash \mathbf{b} 2$ was over-expressed $\sim 30 \%$ in the carcinoma group. After treatment with $250 \mathrm{mg} / \mathrm{kg}$ and $500 \mathrm{mg} / \mathrm{kg}$ body weight of Hesa-A, erbb2 levels dropped by $24.1 \%$ and $3.4 \%$ respectively compared to the control carcinoma group $(p<0.01, p<0.0001)$. Moreover, there was a significant relation between erb $\backslash b 2$ mRNA content and observed pathological changes in studied groups $(p<0.05)$. Conclusions: These data provide insight into mechanism(s) by which Hesa-A may improve clinical outcome of oral carcinoma by affecting oncogene erb $\backslash b 2$ expression and suggest Hesa- $A$ as an effective chemotherapeutic agent in treatment of HER+ tumors.
\end{abstract}

Keywords: Hesa-A - oral carcinoma - erb $\backslash$ b2 expression - clinical outcome - rat model - invasion

Asian Pac J Cancer Prev, 16 (16), 6947-6951

\section{Introduction}

Oral cavity cancers are rather common and rank eleventh among other cancers all over the world (Zwetyenga et al., 2003). Tongue cancer is the most common oral cavity neoplasm with an unfavorable prognosis and high metastatic potential (Mesgari et al., 2014). Natural chemotherapeutic agents have always been acknowledged for their vast benefits and less side effects compared to the synthetic anti-neoplastic compounds (Valiyari et al., 2013). HESA-A is an Iranian patented new immunomodulating medication with natural biological compounds (Ahmadi et al., 2010b; Abbasi et al., 2014a). Hesa-A is a mixture of herbal-marine substances and includes Penaeus latisculatus (king prawn), Carumcarvi and Apiumgraveolens with antineoplastic properties (Ahmadi et al., 2010a). Studies on anti-neoplastic properties of Hesa-A showed promising results in patients with advanced colorectal cancer and end staged breast cancer patients with choroidal metastasis (Ahmadi et al., 2005; Ahmadi et al., 2009). Analysis of the chemical composition of HESA-A has shown that it is composed of $50 \%$ inorganic substance, $45 \%$ organic substance (aminoenthraquinone) and 5\% water. The inorganic component consists of calcium carbonate, magnesium phosphate and sulfate, potassium and sodium and elements such as aluminum, cobalt, potassium, chrome, iron, zinc, bromine and strontium at high concentrations (Mehdipour et al., 2013a).

Epidermal growth factor receptor (EGFR) protooncogene maps to 7p13-q22, and encodes a transmembrane protein whose activation by ligands such as epidermal growth factor or transforming growth factor alpha triggers a cascade of intracellular biochemical processes involved in cellular proliferation, differentiation, migration, and anti apoptotic pathways; it seems to play a significant role in cancer cell proliferation, survival, and mobility (Massano et al., 2006; Abbasi et al., 2014c). Its overexpression is common in many malignancies, including breast, prostate, lung, and bladder cancers, correlating with poor prognosis (Lippman and Hong, 2001). The erb $\backslash \mathrm{b} 2$ gene is one of the most studied biomarkers in OSCC. The high expression of $\mathrm{erb} / \mathrm{b} 2$ has been associated with a poor prognosis and the combined expression of p53, cyclin D1, and EGFR has

${ }^{1}$ Drug Applied Research Center, ${ }^{2}$ Student Research Committee, ${ }^{5}$ Department of Medical Biotechnology, Faculty of Advanced Medical Sciences, ${ }^{4}$ Department of Hematology, Faculty of Medicine, Tabriz branch Islamic Azad University, Tabriz, ${ }^{3}$ Department of Oral Medicine, Faculty of Dentistry, Shahid Beheshti University of Medical Sciences, Tehran, Iran *For correspondence: jahanbanr@ tbzmed.ac.ir 
been correlated with an unfavorable prognosis in OSCC patients (Abusail et al., 2013). Although Hesa-A showed satisfactory results in some end staged and metastatic tumors, however its effects still need to be tested on other aggressive tumors including oral carcinoma. Moreover, no study evaluated its effects at a molecular level to discern the possible underling mechanism of action. Hence, in following study we evaluated the therapeutic effects of two doses of Hesa-A on erb $\backslash \mathrm{b} 2$ expression as a main prognosticator for oral cancer.

\section{Materials and Methods}

\section{Animals}

Sixty adult male Sprague Dawley rats (3-3.5 monthold) with an average weight of $220 \mathrm{~g}$ were obtained from the Animal Lab of Tabriz University of Medical Sciences. The animals were quarantined and acclimatized to laboratory conditions for 2 weeks. During the study, each rat was housed in a metal cage, with hardwood chips for bedding in an air-conditioned room under 12-h light/12-h dark cycles at a temperature of $22 \pm 2^{\circ} \mathrm{C}$. Steps for 4-NQO induced oral cancer described by Mehdipour et al and our previous works (Mehdipour et al., 2013b; Abbasi et al., 2014a) .

\section{Preparation and drug administration to rats}

HESA-A powder was dissolved for an hour in normal saline solution acidified with $\mathrm{HCl}$. The resultant solution was treated with $\mathrm{NaOH}$ to reach a final $\mathrm{pH}$ of 7.4. The solution was filtered and administered to rats by gavage three times a week at doses of 250 and $500 \mathrm{mg} / \mathrm{kg}$ body weights. Normal saline and 4NQO (30 ppm) were used as negative and positive controls, respectively. Sixty 12-week-old male Sprague Dawley rats, were randomly divided into 5 groups of 12 animals each. Group i and ii served as carcinoma groups that received 500 and $250 \mathrm{mg} /$ $\mathrm{kg}$ body weight doses of Hesa-A, respectively. Group (iii) served as untreated carcinoma group. Group (iv) served as the control and was fed on basic diet and tap water without 4-NQO and Group (v) served as healthy control that received $500 \mathrm{mg} \mathrm{kg}$ oral doses of Hesa-A three times a week (Table 1).

\section{RT-Real time PCR}

The Q- PCR was done according to our previous works (Esfahlan et al., 2011a; Esfahlan et al., 2011b; Esfahlan et al., 2012). Briefly ,total RNA (5 $\mu \mathrm{g})$ extracted from homogenized fine powder of removed tongue tissues were reverse transcribed to cDNA using Revert Aid first strand cDNA synthesis kit (fermentase). The resulting cDNA was diluted 1:20 fold and the PCR reaction was performed with $2.5 \mu 1 \mathrm{cDNA}, 10 \mathrm{pM}$ each forward and reverse primers, 12.5 $\mu 1$ SYBR Green PCR Master Mix (Fermentase) in a final volume of $25 \mu 1$. The thermal profile for the real-time Q-PCR was $95^{\circ} \mathrm{C}$ for $10 \mathrm{~min}$ and followed by 45 cycles of $95^{\circ} \mathrm{C}$ for 15 seconds and $60^{\circ} \mathrm{C}$ for $1 \mathrm{~min}$. Rat primers designed by Quant prime software as following : ERBB2 (NM_017003.2): TCTCCGTGACCTCAGTGTCTTC-3' (forward), 5'-GTGTCAATGAGTACGCGCCATC - 3' (reverse); GAPDH (AF 106860): 5' -ATGACTCTACCCACGGCAAG-3' (forward), 5'-CTGGAAGATGGTGATGGGTT-3'. The gene expression was expressed as fold change from the GAPDH level which is calculated as $2-\Delta \Delta \mathrm{Ct}$. Following, fold changes expressed as percents by this formula for easy understanding of the results:

Fold change $($ percent $)=$ fold change $\times 100$

\section{Ethics}

All the ethical and the humanity considerations were performed according to the Helsinki humanity research

\section{Table 1. Characteristics of the Experimental Groups in this Study}

\begin{tabular}{|c|c|c|c|c|c|}
\hline $\begin{array}{l}\text { Experimental } \\
\text { Groups }\end{array}$ & $\begin{array}{c}\text { Names of } \\
\text { Groups }\end{array}$ & $\begin{array}{l}\text { Sort of } \\
\text { treatment }\end{array}$ & $\begin{array}{l}\text { Number of } \\
\text { total cases }\end{array}$ & $\begin{array}{c}\text { Number of } \\
\text { examined cases }\end{array}$ & $\begin{array}{c}\text { Number of } \\
\text { dead cases }(n)\end{array}$ \\
\hline \multirow{3}{*}{ Carcinoma Groups } & $\mathrm{i}$ & 4-NQO & 12 & 12 & 0 \\
\hline & ii & 4-NQO+250 mg/kg HESA-A & 12 & 12 & 0 \\
\hline & iii & 4-NQO+500 mg/kg HESA-A & 12 & 9 & 3 \\
\hline \multirow[t]{2}{*}{ Healthy Groups } & iv & None & 12 & 11 & 1 \\
\hline & $\mathrm{V}$ & $500 \mathrm{mg} / \mathrm{kg} \mathrm{HESA}-\mathrm{A}$ & 12 & 10 & 2 \\
\hline
\end{tabular}

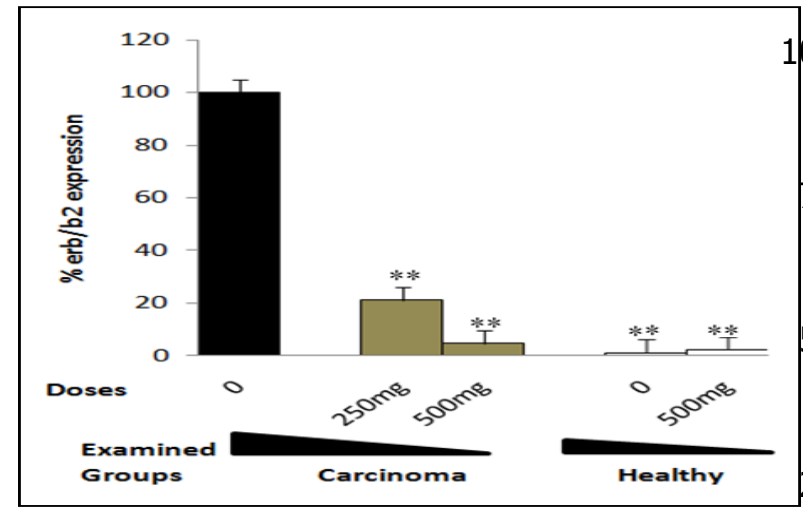

Figure 1. Frequency of Observed Pathological Changes in Groups

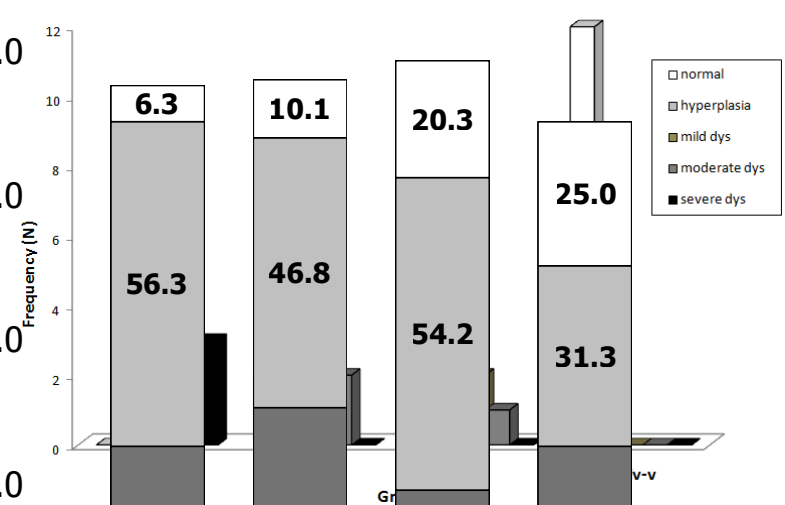

Figure 2. Effect of Two Doses of Hesa -A on erb/b2 Gene Expression in Rat Model of Oral Carcinoma 
declaration during the experiments and the euthanasia of the animals. All the animals' experiments were approved by the Ethics Committee of the Tabriz University of Medical Sciences.

\section{Data analyses}

The data were analyzed using SPSS No 16. One-Way Analysis Of Variance (ANOVA) was used to compare fold change difference in groups followed by multiple comparisons with the LSD post-hoc test. Chi square test was used to evaluate relation between erb $\backslash \mathrm{b} 2$ content and pathological changes. A p value $<0.05$ was considered significant.

\section{Results}

\section{Histopathological changes in studied groups}

After 12 weeks treatment with 4NQO, precancerous lesions in the oral cavity including hyperplasia and three types of dysplasia (mild, moderate and severe) were detectable. Almost all the rats in carcinoma group displayed hyperplasia followed by all types of dysplasia (dys). Histopathologial changes in studied groups were as following:

Group I (Untreated carcinoma group) which was treated with 4NQO, (0\9) normal, $1 \backslash 9$ hyperplasia and $8 \backslash 9$ dysplasia (2/8 mild dysplasia, 3/8 moderate dysplasia and $3 / 8$ severe dysplasia) were recognized.

In Group II (Hesa -A 250mg kkg + 4NQO): 2\11 of lesions were normal, $3 \backslash 11$ hyperplasia and $5 \backslash 11$ showed dysplasia (3/11 mild, 2/11 moderate and 0/11 severe).

In Group III (Hesa -A 500mg $\backslash k g+4 N Q O$ ): $3 \backslash 10$ of lesions were normal, $3 \backslash 10$ were hyperplasia and $3 \backslash 10$ showed different stages of dysplasia including 2/10 mild, $1 / 10$ moderate and $0 / 10$ severe dysplasia.

All cases in Group IV and V (Healthy controls) displayed a normal histology in examination (12\12 normal) (Figure 1). There was no significant difference between healthy group and healthy group which was treated with $500 \mathrm{mg} / \mathrm{kg}$ body weight of Hesa-A ( $>0.05)$. Pathological changes significantly were different between carcinoma group and Hesa-A treated carcinoma groups $(\mathrm{P}<0.01)$.

Effect of Hesa-A on mRNA expression of Erb\b2 in rat tongue tissues

The results of real time PCR indicated that compared to healthy group, erb $\backslash \mathrm{b} 2$ over expressed $\sim 40 \%$ in untreated carcinoma group $(\mathrm{p}<0.05)$ (data not shown). Moreover, quantification of erb $\backslash \mathrm{b} 2 \mathrm{mRNA}$ showed that compared to untreated carcinoma (iii), treatment of carcinoma groups (iv) and (v) with two oral doses of Hesa-A $(250 \mathrm{mg} / \mathrm{kg}$ and $500 \mathrm{mg} / \mathrm{kg}$ per body weight) resulted in $24.1 \%$ and $3.4 \%$ decrease in erb $\backslash \mathrm{b} 2$ level, respectively that was statistically significant $(\mathrm{P}<0.05, \mathrm{p}<0.0001)$. Dose $500 \mathrm{mg} / \mathrm{kg}$ of Hesa-A decreased erb $\backslash \mathrm{b} 2 \mathrm{mRNA} \sim 5$ folds more than dose $250 \mathrm{mg} /$ $\mathrm{kg}(\mathrm{p}<0.01)$. Furthermore, erb $\backslash \mathrm{b} 2 \mathrm{was}$ not detectable in either of healthy control and healthy control that was treated with $500 \mathrm{mg} / \mathrm{kg}$ of Hesa-A (P>0.05). Observed $\%$ mRNA changes in studied groups shown in Figure 2.

Relation between er $\backslash \backslash b 2 \mathrm{mRNA}$ and pathological changes in samples

Group that received $500 \mathrm{mg} / \mathrm{kg}$ body weight doses of hesa-A, all $3 \backslash 3(100 \%)$ normal lesions expressed low mRNA level of erb/b2 whilst in hyperplasia lesions, $3 \backslash 3$ $(100.0 \%)$ showed a high level of erb/b2. All cases with mild and moderate dysplasia 2\2 (100.0\%) and 1/1 (100\%) respectively, represent high amount of erb/b2 content $(\mathrm{P}=0.032)$ (Table 2).

In group that was given $250 \mathrm{mg} / \mathrm{kg}$ oral doses of Hesa-A, erb/b2 was not detectable in all $2 \backslash 2(100 \%)$ of normal lesions, whilst in hyperplasia lesions, $3 \backslash 3(100.0 \%)$ showed a high level of erb/b2 level and $3 \backslash 3(100.0 \%)$ and

Table 2. Relation between erb/b2 mRNA Expression and Tumor Stage in Carcinoma Group Treated with Oral doses of $500 \mathrm{mg} / \mathrm{kg}$ Hesa-A

\begin{tabular}{|c|c|c|c|c|}
\hline \multicolumn{2}{|c|}{$500 \mathrm{mg} / \mathrm{kg}$ HESA-A } & \multicolumn{2}{|c|}{ ERB/B2 Expression } & \multirow[t]{2}{*}{ Total } \\
\hline & & low & high & \\
\hline \multirow{5}{*}{ Tumor stage } & Normal & $3(100.0 \%)$ & $0(.0 \%)$ & $3(100.0 \%)$ \\
\hline & Hyperplasia & $0(.0 \%)$ & $3(100.0 \%)$ & $3(100.0 \%)$ \\
\hline & Mild dysplasia & $0(.0 \%)$ & $2(100.0 \%)$ & $2(100.0 \%)$ \\
\hline & Moderate dysplasia & $0(.0 \%)$ & $1(100.0 \%)$ & $1(100.0 \%)$ \\
\hline & Severe dysplasia & $0(.0 \%)$ & $0(.0 \%)$ & $0(0.0 \%)$ \\
\hline Total & & $3(33.3 \%)$ & $6(66.7 \%)$ & $9(100.0 \%)$ \\
\hline
\end{tabular}

Table 3. Relation between erb/b2 mRNA Expression and Tumor Stage in Carcinoma Group that Treated with Oral doses of $250 \mathrm{mg} / \mathrm{kg} \mathrm{HESA}-\mathrm{A}$

\begin{tabular}{|c|c|c|c|c|}
\hline \multirow{2}{*}{\multicolumn{2}{|c|}{$250 \mathrm{mg} / \mathrm{kg} \mathrm{HESA}-\mathrm{A}$}} & \multicolumn{2}{|c|}{ ERB/B2 Expression } & \multirow[t]{2}{*}{ Total } \\
\hline & & low & high & \\
\hline \multirow[t]{5}{*}{ Tumor stage } & Normal & $2(100.0 \%)$ & $0(.0 \%)$ & $2(100.0 \%)$ \\
\hline & Hyperplasia & $0(.0 \%)$ & $3(100.0 \%)$ & $3(100.0 \%)$ \\
\hline & Mild dysplasia & $0(.0 \%)$ & $3(100.0 \%)$ & $3(100.0 \%)$ \\
\hline & Moderate dysplasia & $0(.0 \%)$ & $2(100.0 \%)$ & $2(100.0 \%)$ \\
\hline & Severe dysplasia & $0(.0 \%)$ & $0(.0 \%)$ & $0(0.0 \%)$ \\
\hline Total & & $2(20.0 \%)$ & $8(80.0 \%)$ & $9(100.0 \%)$ \\
\hline
\end{tabular}


2/2 $(100 \%)$ cases with mild and moderate dysplasia over expressed high amount of erb/b2 ( $\mathrm{P}=0.019)$.

\section{Discussion}

Oral cancers, the vast majority of which are comprised of squamous cell carcinomas (SCCs), are among the 10 most common cancers worldwide. In spite of extensive treatment (surgery, radiotherapy and/or chemotherapy), OSCC is associated with recurrence and second primary tumors that are responsible for poor overall survival rates $(\sim 50 \%)$ that is not improved significantly over the past three decades and urgent the need for search and development of new effective treatments (Abbasi et al., 2014d).

HESA-A is an Iranian patented natural product with a herbal/marine origin which is showed to possess beneficial anti-tumor effects on some aggressive tumors.

Ahmadi et al in 2005 tested the effects of (Ahmadi et al., 2005) $50 \mathrm{mg} / \mathrm{kg} /$ day of Hesa-A on 24 end staged breast cancer patients with retina choroid metastases. Their findings indicated that $92 \%$ of the patients who received HESA-A at a dosage of $50 \mathrm{mg} / \mathrm{kg} /$ day orally lived with notably improving quality of life through the six months of the study. These patients suffered fewer complications and survived longer.

In the second study by Ahmadi et al in 2009, authors investigated therapeutic effects of HESA-A in Fifty consecutive patients with end-stage colon cancer and liver metastasis. Patients received HESA-A $50 \mathrm{mg} / \mathrm{kg} / \mathrm{d}$ orally in 2 to 3 divided doses for 6 months. The authors concluded that HESA-A is as an effective and safe anticancer drug, in treatment of selected patients with less side effects (Ahmadi et al., 2009) .

In another clinical trial study by Ahmadi et al in 2010 , thirty consecutive patients ( 18 men, 12 women) with endstage cancers and liver metastasis were studied. Patients received HESA-A $50 \mathrm{mg} / \mathrm{kg} / \mathrm{d}$ orally in 2 to 3 divided doses for 3 months. Result showed that a total of $90.4 \%$ of the patients who remained in the study were alive for 12 weeks. No significant hepatic or hematologic adverse effect was seen during the study (Ahmadi et al., 2010b).

In 2013, Mehdipour et al evaluated the effect of two systemic doses of Hesa-A on prevention of induced tongue neoplasm in rats. Their results indicated that Hesa-A possess a dose-dependent inhibitory effects on the development of neoplasms of the tongue (Mehdipour et al., 2013a).

The epidermal growth factor receptor (EGFR)-related family of receptor tyrosine kinases includes human epidermal growth factor receptor (HER1), EGFR, or c-erbB 1; HER2 or c-erbB2 known as her2 \neu; HER3 or c-erbB3; and HER4 or c-erbB4. HER2 is a widely studied oncogene in Head and Neck Squamous Cells Carcinomas (HNSCC) and is well prognosticator of disease (Abusail et al., 2013; Abbasi et al., 2014c). This tyrosine kinase receptor is connected to various downstream signaling targets involved in cellular proliferation, apoptosis, angiogenesis, invasion, and metastasis (Khademi et al., 2013). HER2 encoded by ERBB2 gene and is overexpressesd in over $80 \%$ of all HNSCC as in our study, carcinoma group showed a $30 \%$ overexpression of this oncogene compared to the healthy groups. It is known that her-2 upregulation associate with high p53 content in oral carcinoma which in turn promotes tumor progression (Abbasi et al., 2014b). Our unpublished data indicate that treatment with $250 \mathrm{mg} / \mathrm{kg}$ and $500 \mathrm{mg} / \mathrm{kg}$ body weights of Hesa-A, results in 53.4\% and $13.6 \%$ mRNA level of p53 $(\mathrm{p}<0.05)$, which in case of her-2, Hesa-a showed more remarkable results and dose $250 \mathrm{mg} / \mathrm{kg}$ and $500 \mathrm{mg} / \mathrm{kg}$ body weights decreased erb/b2 oncogene content to $24.1 \%$ and $3.4 \%$ respectively compared to untreated carcinoma group. Furthermore erb/b2 content was associated with improved clinical outcome in our study. No pathological changes observed in healthy group that was treated with $500 \mathrm{mg} / \mathrm{kg}$ of Hesa-A. Altogether, anti tumor properties of Hesa-A on oral carcinoma confirms the results of previous studies which found Hesa-A as an effective and safe chemotherapeutic agent in treatment of aggressive tumors and it seems that the anti tumoral effects of this compound undertake by affecting the expression of main tumor marker genes including p53 tumor suppressor gene and erb/b2. Cooverexpression of these genes leads to important processes which promote tumor invasion and metastasis and Hesa-A with abundant antioxidant content hamper this fatal destiny governed by these two genes.

In conclusion, erb $\backslash \mathrm{b} 2$ is a well known biomarker which its high expression associate with aggression and poor prognosis in many tumor types as well as in oral carcinoma. Significant decrease in level of this prognosticator factor after treatment with Hesa-A and improvement of pathological lesions of oral carcinoma implies that affecting erb $\backslash \mathrm{b} 2$ pathway could be considered as a mechanism of action for potent anti tumor activities of this extract on different progressive human malignancies including oral carcinoma.

\section{References}

Abbasi MM, Jahanban-Esfahlan R, Monfaredan A, et al (2014a). Oral and IV dosages of doxorubicin-methotrexate loadednanoparticles inhibit progression of oral cancer by downregulation of matrix methaloproteinase 2 expression in vivo. Asian Pac J Cancer Prev, 15, 10705-11.

Abbasi MM, Khiavi MM, Monfaredan A, et al (2014b). DOXMTX-NPs augment p53 mRNA expression in OSCC model in rat: effects of IV and oral routes. Asian Pac J Cancer Prev, 15, 8377-82.

Abbasi MM, Monfaredan A, Hamishehkar H, et al (2014c). New formulated "DOX-MTX-loaded nanoparticles" downregulate HER2 gene expression and improve the clinical outcome in OSCCs model in rat: the effect of IV and oral modalities. Asian Pac J Cancer Prev, 15, 9355-60.

Abbasi MM, Monfaredan A, Hamishehkar H, et al (2014d). Novel DOX-MTX nanoparticles improve oral SCC clinical outcome by down regulation of lymph dissemination factor VEGF-C expression in vivo: oral and IV modalities. Asian Pac J Cancer Prev, 15, 6227-32.

Abusail M, Dirweesh AM, Salih RA, et al (2013). Expression of EGFR and $\mathrm{p} 53$ in head and neck tumors among sudanese patients. Asian Pac J Cancer Prev, 14, 6415-8

Ahmadi A, Habibi G, Farrokhnia M (2010a). Anticancer effects of HESA-A: an herbal marine compound. Chin J Integr Med, 16, 366-7. 
Ahmadi A, Mohagheghi M, Karimi M, et al (2009). Anticancer effects of HESA-A in patients with metastatic colon cancer. Integr Cancer Ther, 8, 71-4.

Ahmadi A, Mohagheghi M, Karimi M, et al (2010b). Therapeutic effects of HESA-A in patients with end-stage metastatic cancers. Integr Cancer Ther, 9, 32-5.

Ahmadi A, Mohagheghi MA, Fazeli MS, et al (2005). HESA-A: new treatment for breast cancer and choroidal metastasis. Med Sci Monit, 11, 300-3.

Jahanban Esfahlan R, Zarghami N, Jahanban Esfahlan A, et al (2011a). The possible impact of obesity on androgen, progesterone and estrogen receptors (ERa and ERb) gene expression in breast cancer patients. Breast Cancer (Auckl), 227-37.

Jahanban Esfahlan R, Zarghami N, Rahmati-Yamchi M, et al (2011b). Quantification of steroid receptors gene expression in breast cancer patients: possible correlation with serum level of adipocytokines. J Cancer Therapy, 2, 659-65.

Jahanban Esfahlan R, Zarghami N, Valiyari S, et al (2012). Adiponectin can affect ER signaling in obese breast cancer patients. J Cancer Therapy, 3, 115-21

Khademi B, Khademi B, Ghaderi A, et al (2013). Early detection of serum levels of HER-2 in patients with head and neck squamous cell carcinoma. Iran J Otorhinolaryngol, 25, 161-8.

Lippman SM, Hong WK (2001). Molecular markers of the risk of oral cancer. $N$ Engl J Med, 344, 1323-6.

Massano J, Regateiro FS, Januario G, et al (2006). Oral squamous cell carcinoma: review of prognostic and predictive factors. Oral Surg Oral Med Oral Pathol Oral Radiol Endod, 102, 67-76.

Mehdipour M, Taghavi ZA, Mesgari AM, et al (2013a). Evaluation of the effect of two systemic doses of hesa-a on prevention of induced tongue neoplasm in rats. J Dent Res Dent Clin Dent Prospects, 7, 218-24.

Mehdipour M, Taghavi Zenouz A, Mesgari Abbasi M, et al (2013b). Evaluation of the effect of two systemic doses of HESA-A on prevention of induced tongue neoplasm in rats. $J$ Dent Res Dent Clin Dent Prospects, 7, 218-24.

Mesgari Abbasi M, Moradzadeh Khiavi M, Monfaredan A, et al (2014). DOX-MTX-NPs augment p53 mRNA expression in OSCCs model in rat: the effect of IV and Oral dosages. Asian Pac J Cancer Prev, 15.

Valiyari S, Jahanban-Esfahlan R, Zare Shahneh F, et al (2013). Cytotoxic and apoptotic activity of Scrophularia oxysepala in MCF-7 human breast cancer cells. Toxicological \& Environmental Chemistry, 95, 1208-20.

Zwetyenga N, Majoufre-Lefebvre C, Siberchicot F, et al (2003). [Squamous-cell carcinoma of the tongue: treatment results and prognosis]. Rev Stomatol Chir Maxillofac, 104, 10-7. 